\title{
COVID-19 and Down's syndrome: are we heading for a disaster?
}

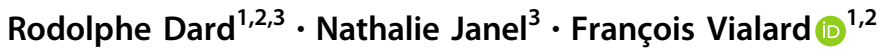

Received: 21 April 2020 / Revised: 5 May 2020 / Accepted: 7 July 2020 / Published online: 20 July 2020

(c) European Society of Human Genetics 2020

The SARS-CoV-2 has spread around the world for the last 5 months, leaving no country unaffected. COVID-19 is a terrible, highly contagious infectious disease. The mortality rate has been estimated up to 30 times than that of influenza [1]. Severe acute respiratory syndrome, cardiomyopathy, and a cytokine storm are the key lethality factors. Importantly, older age, diabetes, obesity, hypertension, and cardiovascular disease are conventional risk factors associated with admissions to and death in an intensive care unit [2]. According to the World Health Organization, the mortality rates in developed countries are around $15 \%$ in people aged 80 and over but only $0.2 \%$ in the under 30s [3]. Thankfully, COVID-19 appears to spare healthy children [4].

In this time of crisis, we believe that it is particularly important to consider people with Down's syndrome (DS). In Europe and North America, the prevalence of DS is about 1 in 1200 - meaning that more than 1 million adults and children live with DS. This syndrome is notably associated with the development of congenital heart disease, sleep apnoea, obesity, diabetes, premature ageing, and higher sensitivity to upper respiratory tract infections. Each of these conditions is likely to make people with DS-even children-more prone to severe COVID-19. As reported in 2009, the mortality rate among people with DS during the H1N1 flu pandemic has been estimated up to 300 times than observed in the general population, but only considering 60 patients [5]. In the absence of widespread vaccination availability, SARS-CoV-2 might take a similar course through the world as H1N1, and had an enormously disproportionate impact on the DS

Rodolphe Dard

Rodolphe.dard@ght-yvelinesnord.fr

1 Genetics Department, CHI Poissy St Germain-en-Laye, F-78300 Poissy, France

2 Université Paris-Saclay, UVSQ, INRAE, ENVA, BREED, 78350 Jouy-en-Josas, France

3 Université de Paris, BFA, UMR 8251, CNRS, F-75213 Paris, France community. Thus, the lethality of COVID-19 might lead to a dramatically high mortality rate-over 50\%—among young adults and children with DS and comorbidities, and probably an even higher value among older adults with DS.

Given that people with DS are often intellectually impaired, measures designed to prevent transmission of the virus will certainly be more difficult to apply in this population. Furthermore, most adults with DS live in institutions where the risk of contagion is significant or with their elderly parents, who themselves constitute a high-risk group.

In these chaotic times, healthcare systems have to focus on essential care. Under these circumstances, medical genetics centres tend to be closed-leaving people with DS without specialist follow-up and specific guidance. In view of the above, we want to warn healthcare providers and families about the higher risk of severe COVID-19 among people with DS-including children.

We fear that tackling the broader COVID-19 crisis might make the health authorities lose sight of a potential disaster among people with DS. Accordingly, we insist on the importance of early containment, care provision, and easily understandable advice for especially vulnerable people with DS. More broadly, we must be attentive to the needs of people with mental and immune impairments, such as those caused by 22q11.2 deletion-the second most frequent cytogenetic disease.

\section{Compliance with ethical standards}

Conflict of interest The authors declare that they have no conflict of interest.

Publisher's note Springer Nature remains neutral with regard to jurisdictional claims in published maps and institutional affiliations.

\section{References}

1. Baud D, Qi X, Nielsen-Saines K, Musso D, Pomar L, Favre G. Real estimates of mortality following COVID-19 infection. Lancet Infect Dis. 2020. https://doi.org/10.1016/S1473-3099(20)30195-X. 
2. Zhou F, Yu T, Du R, Fan G, Liu Y, Liu Z, et al. Clinical course and risk factors for mortality of adult inpatients with COVID-19 in Wuhan, China: a retrospective cohort study. Lancet Lond Engl. 2020;395:1054-62.

3. WHO. Report of the WHO-China joint mission on coronavirus disease 2019 (COVID-19). WHO. 2020. https://www.who.int/docs/ default-source/coronaviruse/who-china-joint-mission-on-covid-19final-report.pdf.
4. Lu X, Zhang L, Du H, Zhang J, Li Y, Qu J, et al. SARS-CoV-2 infection in children. N Engl J Med. 2020. https://doi.org/10.1056/ NEJMc2005073.

5. Pérez-Padilla R, Fernández R, García-Sancho C, FrancoMarina F, Aburto O, Lopez-Gatell H, et al. Pandemic (H1N1) 2009 virus and Down syndrome patients. Emerg Infect Dis. 2010; $16: 1312-4$. 